\title{
¿Por qué publicar en la revista de la AAOT?
}

\author{
Dr. Ignacio Arzac Ulla \\ BR Traumatología, Azul, Buenos Aires, Argentina
}

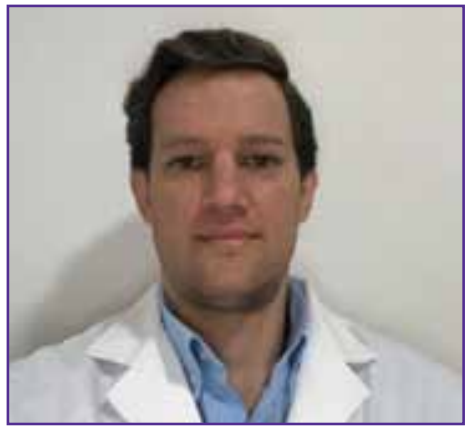

$\mathrm{L}$ a Real Academia Española define investigar como "indagar para descubrir algo" o "realizar actividades intelectuales y experimentales de modo sistemático con el propósito de aumentar los conocimientos sobre una determinada materia".

Siguiendo ese concepto, realizar un trabajo científico consiste en un proceso ordenado y sistemático de análisis y estudio sobre un tema. Es evolutivo, dinámico y cambiante. Publicar un trabajo científico es contribuir a la construcción del conocimiento. La dinámica de la investigación hace que muchos conceptos utilizados en el pasado sean refutados en la actualidad, y viceversa. El objetivo de un trabajo científico es obtener conocimiento o aumentar el ya existente a partir de una premisa. Un artículo publicado hace un aporte a la generación del conocimiento, da el puntapié inicial para que otros continúen y avancen en la investigación.

Para Karl Raimund Popper, la cualidad más importante del pensamiento científico es que sea refutable. La refutabilidad es una característica propia y es una cualidad sine qua non para que un conocimiento sea científico. Si no se puede refutar, el conocimiento no es científico.

Los trabajos de científicos son una herramienta invaluable con la que contamos los médicos, nos permiten estudiar en profundidad un tema y son una forma aceptada de divulgación para el avance de la ciencia.

La revista de la Asociación Argentina de Ortopedia y Traumatología trabaja activamente para que ese conocimiento científico llegue a cada traumatólogo. Es la revista de traumatología argentina más importante en la actualidad. Presenta numerosas indexaciones, entre ellas, REDIB (Red Iberoamericana de Innovación y Conocimiento Científico), DOAJ (Directory of Open Access Journals), JournalTOCs, Dialnet, portal de difusión de la producción científica hispana, Harvard Library, Hallam Library, WorldCat, AmeliCA.

A partir de 2011, la Revista de la Asociación Argentina de Ortopedia y Traumatología se encuentra "en línea" en SciELO (Scientific Electronic Library Online). Los trabajos se identifican con el CrossRef DOI (Digital Object Identifier) y los artículos publicados son traducidos al inglés y se hallan en Google Scholar.

Pero, ¿por qué publicar en nuestra revista? Tenemos una plataforma ágil para publicar los trabajos, presentamos garantía de calidad mediante la evaluación calificada de los manuscritos y la revista cuenta con exposición e impacto internacional mediante sus indexaciones.

Nos falta un paso más que es la indexación en PubMed, tan ansiada y querida por todos nosotros. El trabajo no es fácil, nos comprometimos a publicar 6 números por año, eso requiere una labor mucho más activa y participativa de todos. Incorporamos los pódcast, visualización en redes sociales, agregamos editores de sección, revisores y todo lo necesario para mejorar la calidad en las publicaciones. El objetivo de estos revisores es fortalecer y enriquecer los trabajos científicos, marcar sus debilidades, mejorarlos aportando su experiencia y conocimiento en la materia.

Pretendemos formar nuevos autores y es por eso que la revista de la AAOT está para ayudarlos a que su trabajo sea publicado. 